\title{
A EVOLUÇÃO DO OVO: QUANDO LEITURA E LITERATURA SE ENCONTRAM NO ENSINO DE CIÊNCIAS
}

\author{
Leandro Siqueira Palcha* \\ Odisséa Boaventura de Oliveira**
}

RESUMO: Neste trabalho, propomos que a leitura e a literatura sejam usadas nas aulas de ciências com o objetivo de contextualizar o conhecimento científico, pois consideramos que ambas carregam marcas históricas e sociais que oferecem margem para transformá-las e ampliá-las. Apresentamos um estudo com licenciandos em Ciências Biológicas envolvendo a leitura e a produção de textos sobre a teoria da Evolução Biológica. Selecionamos um conto denominado "A evolução do ovo" e o plano de ensino proposto para sua utilização, com objetivo de analisar o funcionamento da interface entre leitura e literatura na produção e mediação do conhecimento científico. Encontramos alguns aspectos extra, intra e intertextuais em relação ao texto produzido, além de pontos e contrapontos pertinentes ao funcionamento da leitura no ensino de ciências.

Palavras-chave: Leitura. Literatura. Ensino de Ciências.

THE EVOLUTION OF EGGS: WHEN READING AND LITERATURE MEET IN SCIENCE TEACHING

ABSTRACT: In this paper we propose that reading and literature be used in science classes in order to contextualize scientific knowledge, for we consider that both carry historical and social brands that offer room for its transformation and expansion. We present a study with the participation of undergraduates in Biological Science involving reading and producing texts on the theory of Biological Evolution. We selected a short story called "The evolution of eggs" and the syllabus proposed for its use in order to examine the functioning of the interface between reading and literature in the production and mediation of scientific knowledge. We found some extra, intra and inter-textual aspects in relation to the text produced in addition to points and counterpoints that are relevant to the operation of reading in science teaching.

Keywords: Reading. Literature. Science Teaching. 


\section{INTRODUĈ̣̃O}

Em decorrência do desafio de a escola contribuir com a formação de estudantes-leitores, inúmeros pesquisadores têm voltado o foco dos estudos para as problemáticas envolvendo as práticas de leitura e o ensino de ciências (ALMEIDA, CASSIANI e OLIVEIRA, 2008; ALMEIDA, NARDI e BOZELLI; 2009; ALMEIDA e SORPRESO, 2011; ANDRADE e MARTINS, 2006; CASSIANI, 2006; FERREIRA e QUEIROZ, 2011; GIRALDELLI e ALMEIDA, 2008; NASCIMENTO, MARTINS, 2011; SILVA e ALMEIDA, 2005; ZANOTELLO, 2011). Com efeito, isso reflete a atenção que os processos e estratégias discursivas da leitura vêm adquirindo para compreensão sociocultural da ciência presente na contemporaneidade. Nessa direção, defendemos que as práticas escolares de leitura tornam-se responsabilidade de todas as áreas de ensino e de todos os professores que fazem parte do processo educativo e estão envolvidos nas condições de sua produção.

A prática de leitura destaca-se como um processo construído por marcas sociais, históricas, políticas e ideológicas que expressam o modo como os sentidos são construídos na sociedade. Isso significa que a leitura é produzida por condições de produção (situação da enunciação, contexto histórico, interlocutores) que permitem a compreensão da realidade pelos sujeitos (ORLANDI, 2006). Nesses termos, as relações de sentido não se constituem especificamente entre o leitor e o texto, mas, sobretudo, "no espaço discursivo dos interlocutores" (ORLANDI, 2006) ou seja, na dinâmica interativa entre o leitor real e o leitor virtual. O leitor virtual é designado como o "leitor imaginário, aquele que o autor imagina (destina) para seu texto e para quem ele se dirige. Tanto pode ser um seu 'cúmplice' quanto um seu 'adversário"' (ORLANDI, 2012, p.10).

Queremos, portanto, assinalar que as relações de interação entre os interlocutores desencadeia, por meio de uma historicidade da leitura, uma tessitura de sentidos que carrega e determina o conjunto de significações. Por conta disso, o processo de leitura de cada sujeito traz consigo experiências sociais que foram apropriadas por condições, contextos e práticas sociais que, em particular, se constituem nas histórias de leitura, do texto e do leitor (ORLANDI, 2012).

Mas, por outro lado, na instituição escolar encontra-se um conhecimento bastante raso e generalizado a respeito da prática de leitura, como escreve Gallo (2008, p.90): no “discurso didático-pedagógico o trabalho de 'leitura' se confunde com o trabalho de decodificação, no nível da matéria gráfica, e de 'avaliação' (não é para ler, é para corrigir) no nível da escrita". Para tanto, na perspectiva discursiva, é necessário tentar reverter essa situação instaurada na/pela escola para que a leitura realizada contribua com a produção de sentidos, ao longo da escolaridade.

Nesse caso, fazemos referência às estreitas relações entre a leitura e a literatura, na medida em que, como componente social, para que a literatura exista "é preciso que alguém a escreva e que outro alguém a leia. Ela só existe enquanto obra neste intercâmbio social” (LAJOLO, 1990, p.16). Assim, a literatura, em dado momento sócio-histórico, faz parte de uma construção artística e cultural 
da sociedade, tendo em vista que, segundo Magnani (2011, p.142), "a literatura mobiliza a imaginação, a diversidade de opções, estimula a busca de alternativas” e, mais ainda, na leitura, “devemos ser coautores não só dos fracassos, mas também da luta pela participação na construção da sociedade que interesse não apenas alguns, mas principalmente, aos exilados da palavra” (MAGNANI, 2011, p.142).

Tanto o funcionamento social da literatura quanto o da leitura não pode ser considerado um fenômeno unilateral e diretivo da produção de sentidos, mas um processo simbólico plural e reflexivo de compreensão da realidade. $\mathrm{Na}$ relação com o saber, ambos os processos operam sob os processos de significação, e, portanto, a escola como uma instituição produtora do conhecimento precisa promover reflexões acerca da relação de sentidos entre o ensino e a linguagem.

Nessa perspectiva, realizamos um estudo em uma turma de licenciatura em Ciências Biológicas usando como referencial teórico-metodológico a Análise de Discurso (AD) francesa, envolvendo a leitura e a produção de textos sobre Evolução Biológica. Dentre os textos produzidos pelos licenciandos, selecionamos um conto literário chamado "A evolução do ovo", com o objetivo de analisar o funcionamento da interface entre leitura e literatura na produção e mediação do conhecimento científico no ensino de ciências. Pelos caminhos trilhados, encontramos alguns pontos e contrapontos pertinentes a essa interface.

\section{LEITURA E LITERATURA: OS CAMINHOS DO DISCURSO NA ESCOLA}

De maneira geral, o processo de leitura se constitui por meio da incompletude, ou seja, a prática de leitura abrange uma abertura da significação para múltiplos sentidos que estão aquém e além do texto (ORLANDI, 2006). Por conseguinte, toda prática de leitura envolve um esforço intelectual do leitor, assim como requer ajustes interpretativos visando considerar os sentidos implícitos e explícitos que compõem o texto. Nessa medida, destacamos que "quando se lê, considera-se não apenas o que está dito, mas também o que está implícito: aquilo que não está dito e que também está significando" (ORLANDI, 2012, p.13).

Não obstante, a interpretação, engendrada pela ideologia (PÊCHEUX, 2009; ORLANDI, 2003), configura-se como se os sentidos fossem evidentes. No entanto, os sentidos não são manifestados arbitrariamente, muito menos são transparentes. Existe uma relação implícita entre os sentidos e os discursos sociais que é interiorizada no interdiscurso ou memória discursiva dos sujeitos. Como afirma Orlandi (2001, p.59), "o interdiscurso é o conjunto de dizeres já ditos e esquecidos que determinam o que dizemos, sustentando a possibilidade do dizer. Para que nossas palavras tenham sentido é preciso que já tenham sentido".

Convém, então, observar que também existem diferentes modos de leitura para um texto no ensino de ciências, seja ela feita por diferentes leitores ou pelo mesmo sujeito em momentos diferentes (ALMEIDA, SILVA e MACHADO, 2001; CASSIANI, 2006, CASSIANI e NASCIMENTO, 2006; DIAS e ALMEIDA, 
2010; MICHINEL, 2006; OLIVEIRA, 2011). Isso porque a produção de sentidos de um texto passa pela relação com outros textos já lidos em outras épocas, e a esse fenômeno chamamos de intertextualidade (ORLANDI, 2006). Podemos, assim, assinalar que o processo de leitura trabalha com o imaginário do leitor, sendo importante oferecer oportunidades para que ele exercite sua capacidade de compreensão (ORLANDI, 2001).

No presente estudo, optamos por trabalhar com leitura e literatura, por acreditarmos ser necessário construir condições para que o aluno possa relacioná-las à prática social. $\mathrm{O}$ funcionamento de um texto literário também precisa ser pensado como parte de um processo social ou, ainda, como sustenta Candido (2000), a literatura é constituída pelo elemento social, nela pode-se observar a influência do meio na expressão artística em determinada época. Dito de outra forma, a literatura se constrói, normalmente, em um aspecto de integridade e complementação da expressão artística influenciada por fatores sociais diversos. Por conta disso,

Tratar de leitura e literatura é tratar de um fenômeno social que envolve as condições de emergência e utilização de determinados escritos, em determinadas época; é pensá-las do ponto de vista de seu funcionamento sócio-histórico, antes e para além de platônicos e redutores juízos de valor. (MAGNANI, 2011, p.43).

Segundo Lajolo (1990), as instituições, mais ou menos especializadas, são as principais responsáveis por introduzir e balizar julgamentos sobre o aspecto literário ou não literário de uma obra. Vale, então, dizer que a escola é uma das instituições fundamentais no endosso de status literário de uma obra, na medida em que a "instituição escolar é a que há mais tempo e com maior eficiência vem cumprindo seu papel de avalista e fiadora da natureza e valor literários dos livros em circulação" (LAJOLO, 1990, p.18).

A relação leitura-literatura também pode ser prazerosa quando substitui uma concepção trivial de leitura, como meramente passiva e reprodutora de um texto. Em suma, concordamos com Lajolo ao defender que a linguagem literária instaura um espaço de interação entre as subjetividades (autor-leitor) que escapa das condições normativas da vida cotidiana, uma vez que ela abre espaço para uma autonomia que "não se desfaz na última página do livro, no último verso do poema, na última fala da representação. Permanece ricocheteando no leitor, incorporando como vivência, erigindo-se em marco do percurso de leitura de cada um" (LAJOLO, 1990, p. 43). Além do mais,

pode se aprender a gostar de ler textos de qualidade literária (e gostar de aprender). Saber e prazer não são excludentes como querem aqueles que temem a ruptura, porque não querem perder o poder que o saber lhes confere. Para poder conservar ou transformar é preciso conhecer e se arriscar, e esse deve ser um direito conquistado por todos" (MAGNANI, 2011, p. 136, grifo da autora). 
Devemos, portanto, pensar em formas de descontruir modelos de ensino pautados por interpretações automáticas de leitura, viabilizando a heterogeneidade de princípios sociais, culturais e históricos que se constituem entre os sentidos e os sujeitos. Como sustenta Magnani,

\begin{abstract}
o estudo crítico e comparativo do texto como um todo (condições de emergência, utilização, funcionamentos conformes e disfuncionamentos) se apresenta como uma forma de desmistificar e desautorizar modelos; de recuperar o prazer de saber que há muitos jeitos de ler e escrever e que não são casuais; de perceber que o prazer não se compra em lojas, nem é automático, mas depende da emoção e da percepção mais ou menos clara do trabalho particular da linguagem e de formas, e tampouco é incompatível com o saber; que a leitura é também novidade e ruptura e só será agente de transformação na medida em que for resultado e lugar de transformação (MAGNANI, 2011, p.140 - 141).
\end{abstract}

Nesse passo, é fundamental que os alunos sejam atuantes na apropriação e mobilização do saber, bem como que os professores construam, situem e explorem as condições de produção de textos, visando a produzir mediações problematizadoras do conhecimento.

\title{
EVOLUC̣ÃO BIOLÓGICA: A MEDIAC̣ÃO DO CONHECIMENTO
}

A Evolução Biológica se constitui como um dos eixos norteadores das Ciências Biológicas, basicamente em virtude do trabalho de três grandes naturalistas: Jean-Baptiste de Lamarck (1744-1829), Charles Darwin (1809-1882) e Alfred Russel Wallace (1823-1913). Isso porque o discurso evolucionista, em termos gerais, nos conduz a uma série de explicações naturais para a variedade de características dos organismos, desde os traços moleculares, bioquímicos, até o comportamento e os atributos ecológicos (FUTUYMA, 2002).

No que diz respeito à ciência, a Teoria da Evolução é hoje uma teoria amplamente aceita pela comunidade científica, por evidências biogeográficas, genéticas, embriológicas, paleontológicas, entre outras (FUTUYMA, 2002). Constitui-se em um conhecimento legitimado que permite a compreensão de como as espécies evoluíram por processos naturais ao longo do tempo. Mas, como discurso, não podemos restringir o ensino sobre esse tema aos debates e às interpretações da ciência, na medida em que o assunto gerou, e tem gerado, veementes debates por toda sociedade.

Com relação ao ensino básico, estudos afirmam que muitos estudantes possuem conhecimentos alternativos sobre a Evolução Biológica (MEGHILIORATTI, 2004; ALMEIDA e FALCAO, 2005) que persistem na escola mesmo após anos de ensino. Alguns, indicam a necessidade de haver mais estudos em relação à proposta pedagógica desse ensino no currículo básico da Biologia (BIZZO e EL-HANI, 2009). Borges e Lima (2007) salientam que, atualmente, o ensino de Evolução Biológica é relegado a último plano pelos professores, sendo 
constatado que esse tema aparece em último lugar nas tendências de pesquisa entre as diversas temáticas de Biologia. Porto e Falcão (2010) apontam que os discursos de estudantes do Ensino Médio revelam influências religiosas em suas representações imaginárias. Além disso, as influências familiares apareceram como mais relevantes do que aquelas provenientes de atividades escolares. Para os autores, tais fatos são sinais de deficiência na abordagem escolar.

Além disso, Costa, Melo e Teixeira (2011), reforçam que os estudantes tendem a acreditar em um tipo de evolucionismo com preceitos ligados à religião, em que um design inteligente é responsável por toda a diversidade biológica, desde a criação dos primeiros seres até o aparecimento das espécies que são encontradas hoje.

No que toca ao livro didático, Almeida e Falcão (2010) observaram que nas edições mais recentes a evolução continua sendo um tema geralmente colocado no final do livro, e o tratamento dado à proposta de Lamarck e Darwin elege este pesquisador como modelo na aplicação do método científico, relegando àquele a condição de um teórico especulador.

No que se refere à formação e à atividade docente, Goedert (2004) analisou aspectos da formação inicial de professores de Biologia em relação ao ensino de Evolução Biológica. Foram observadas algumas dificuldades, como falta de articulação do tema na estrutura curricular do curso; relações conflituosas envolvendo crenças dos alunos quanto às ideias de ancestralidade; conflitos religiosos e elementos do senso comum. Para a pesquisadora, os dados engrossam as pesquisas que apontam a dicotomia teoria e prática de ensino, advogando que a formação de professores não deve favorecer apenas os conhecimentos específicos, mas contemplar o domínio deles com uma significativa abordagem pedagógica que possa subsidiar a sua futura atuação.

Oleques, Bartholomei-Santos e Boer (2011) estudaram as concepções de professores que atuam no Ensino Médio. Eles observaram que nas palavras associadas à evolução havia conotações variadas e contrárias às utilizadas pela ciência atual. Assim, os autores indicaram que há a necessidade de um domínio maior do conhecimento histórico da teoria evolutiva e seus processos por parte desses docentes.

No aspecto geral, Amorim e Rosa (2009) se propuseram a analisar os trabalhos apresentados e publicados nas atas de seis edições do Encontro Nacional de Pesquisa em Educação em Ciências (ENPEC) com o tema Evolução Biológica e destacaram que o panorama indica a dificuldade em se trabalhar com temas controversos e polêmicos que remetam a discussões que vão além da comunidade científica.

$\mathrm{Na}$ base dessas reflexões, é pertinente ressaltar que a constituição de sentidos pelos estudantes se dá a partir de diferentes visões de mundo em complementação ao discurso científico, como apontam Sepúlveda e El- Hani (2004). Da mesma forma, muitas dificuldades em se trabalhar com essa teoria devem-se, principalmente, à sua expansão e transposição literal para outras áreas, como as Ciências Humanas. Nesse caso, Da-Gloria (2009) considera ser razoável, na formação do biólogo, haver elementos históricos, científicos e culturais para mediar discussões sobre esse tema e, assim, conduzir o conhecimento da ciência até outros contextos. 
$\mathrm{Na}$ perspectiva discursiva, a mediação deve favorecer o aspecto de interação entre os interlocutores, descontruindo a lógica de que o professor é o único detentor do conhecimento. Muitas vezes, na escola, o discurso científico constitui-se pela objetividade, o que reflete recortes do conhecimento e conteúdos da ciência reproduzidos com menor ou maior especificidade, garantindo, assim, pela via da neutralidade e ideologia docente, um conhecimento legítimo (ORLANDI, 2006).

Sem tomar consciência do cientificismo e das interpretações ideológicas, os professores afastam os alunos da realidade da ciência, tornando-a um conhecimento absoluto e inquestionável. As práticas pedagógicas que não contemplam abordagens problematizadoras acabam apagando os erros e as falhas do conhecimento científico ao tomar os resultados provisórios como verdades permanentes. Dessa maneira, cria-se um certo distanciamento entre a imagem real da ciência e aquela ideologizada no espaço escolar, uma vez que se perdem os referenciais teóricos e as mediações se sucedem a uma intervenção didática simplificadora que desloca a ciência para um discurso hegemônico, reducionista e facilitador. No caso da formação docente, destacamos a compreensão do domínio científico nos processos de ensino-aprendizagem, para que sejamos formados "em uma idéia contemporânea de ciência, pronta a se conceber capaz de mudanças e autoquestionamentos" (LOPES, 1999, p.108).

\section{OS CAMINHOS E AS CONDIC̣̃̃ES DE PRODUC̦ÃO DA PESQUISA}

A atividade envolvendo a leitura e a produção de textos foi proposta para uma turma de licenciatura em Ciências Biológicas de uma universidade pública, na disciplina de Metodologia do Ensino de Ciências, no primeiro semestre de 2011, integrando parte de uma pesquisa maior (PALCHA, 2012).

Nesses termos, os estudantes analisaram aspectos gerais de textos sobre a Teoria da Evolução Biológica, escritos em diferentes funcionamentos discursivos (científicos, humorísticos, imagéticos etc.) e funcionamentos textuais (charges, histórias em quadrinhos, cartas, artigo científico etc.). O objetivo foi mostrar algumas das possibilidades que o professor tem para trabalhar com o conhecimento científico. Após a leitura dos textos, solicitamos aos licenciandos que, individualmente, elaborassem um novo texto sobre o tema e um plano de ensino de Ciências ou Biologia no qual fossem abordadas estratégias para a leitura do texto produzido.

Foram escritos trinta textos, sendo que selecionamos, para essa análise, um conto literário chamado "A evolução do ovo". Nela, destacamos, de acordo com o dispositivo teórico-metodológico (ORLANDI, 2003), alguns recortes da história, envolvendo aspectos extra, intra e intertextuais, assim como algumas relações (inter)discursivas relativas ao ensino de ciências. 


\section{“A EVOLUC̦ÃO DO OVO”: HISTÓRIA, LEITURA E LITERATURA NO ENSINO DE CIÊNCIAS}

O texto aqui analisado, nomeado pelo estudante como "A evolução do ovo", foi desenvolvido por meio de inserções explicativas que fazem menção ao discurso evolucionista e referência ao conto literário "O patinho feio" ${ }^{1}$. Procuramos, aqui, trazer algumas reflexões sobre a relação entre leitura e literatura que possam contribuir com a apropriação do conhecimento científico no ensino de ciências. Para preservar o anonimato do licenciando, ele será nomeado "Edu".

\section{0 conto: aspectos teóricos, discursivos e literários do texto}

No preâmbulo do texto, são situados alguns aspectos textuais que conduzem o leitor para sua compreensão, além de serem apresentados os contextos e os personagens com os quais a história foi construída. É descrito um cenário no qual há uma pata chocando ovos no ninho até que, em determinado momento, começam a eclodir os filhotes, exceto em um ovo. Mas, concomitantemente, o ambiente é ameaçado por uma chuva tempestuosa e a mamãe-pata resolve migrar do local, deixando ao lado do ovo remanescente um mapa com orientações que guiam o filhote para encontrá-la.

Na sequência, em outro trecho do conto, Edu descreve os momentos em que o filhotinho, tentando se proteger dentro da casca, se depara com a nova realidade tormentosa, mas continua abrigado, ou seja, permanece protegido dentro do ovo. Nesse momento, fica ressaltado que a construção da história é percorrida por trechos que fazem alusão de que, com o passar do tempo, os processos evolutivos de adaptação foram modificando as partes do corpo do filhotinho.

[...] Quando a chuva começou, a mamãe e os outros filhotinhos já tinham ido embora, mas assim que a primeira gota caiu, o outro filhotinho quebrou a casca e pôs seus pés de fora. Vendo que estava chovendo e como não queria se molhar, ele resolveu fazer apenas dois buraquinhos na frente da casca de forma que ele conseguisse enxergar a sua frente, mas que continuasse dentro do ovo protegido da chuva. Contudo, ele ainda tinha um problema: seus pés que já estavam fora do ovo e iriam se molhar. O filhote ficou, então, sentado com os pés fora do ninho e deixou que esses se molhassem na esperança de que se acostumasse. Após um tempo, seus pés começaram a se modificar e se adaptar, eles criaram uma pele entre os dedos, e escamas, e dessa forma ele agora conseguia caminhar no chão molhado sem afundar e muito menos se molhar, visto que as escamas eram impermeáveis e os protegiam na chuva. Munido de seus novos pés, o filhote resolveu, por fim, seguir em frente e realizar sua viagem em busca de sua mãe e de seus irmãos. [...] (EDU, grifos nossos).

Por extensão, o conto descreve o momento em que o filhote, debaixo de chuva e determinado a encontrar a mãe, começa a enfrentar adversidades ambientais as quais reforçam que, ao longo de toda a jornada, ele deveria usar seu instinto de sobrevivência, abandonar o ovo e enfrentar o mundo desconhecido. Ressaltamos, ainda, que o estudante insere, em determinados trechos, alguns sentidos que parecem criar uma relação de interação com o leitor mais experiente no assunto, provocando certas reflexões quanto aos reais mecanismos do processo evolutivo. 
[...] Conforme ele continuou caminhando debaixo de chuva, novas mudanças e adaptações começaram a surgir. Uma camada protetora começou a surgir em todo o seu corpo, uma camada de uma coisa branca e estranha que ele não sabia explicar o que era, mas o deixava aquecido e o melhor de tudo: era impermeável, assim como os pés. Agora, protegido totalmente da chuva, nosso amigo podia finalmente continuar a sua jornada sem preocupação alguma, e assim ele fez. Caminhou por dias e dias, subindo morros, contornando montanhas e modificando-se a cada momento. Conforme ele caminhava, ele viu que muitos outros animais não tinham tido a mesma sorte que ele e tinham morrido, seja devido à chuva em excesso ou devido não terem conseguido caminhar de forma adequada sobre o chão lamacento que existia. Mas por sorte, ele tinha conseguido sobreviver, ele estava adaptado a essas condições e já era muito maior e mais forte se comparado àquele pequeno serzinho que saiu do ovo. [...] (EDU, grifos nossos).

Notamos, ainda, que Edu introduziu uma série de obstáculos ambientais, visando desenvolver as habilidades do personagem como, por exemplo, um perigoso abismo em que este deveria ser capaz de passar sendo que a única maneira possível seria voando. Da mesma forma, após enfrentar seus medos e ultrapassar a barreira geográfica, o patinho resolveu continuar sua jornada voando próximo ao sol, ao mesmo tempo em que ocorreram outras modificações em seu corpo estreitamente relacionadas aos fatores ambientais.

Para encerrar o texto, percebemos que o licenciando-autor indicou que o personagem logrou êxito na sua longa viagem, isso porque o patinho chega a um maravilhoso lago e encontra a mãe com outros seres, muito parecidos com ele, mas com algumas diferenças que conduzem ao desfecho na história (evolutiva).

[...] Quando ele finalmente encontrou a sua mãe, ele descobriu quem ele era: um belo cisne. Ele descobriu que seus pés eram mesmo adaptados para a água, seus braços eram asas feitas para voar e a cobertura do seu corpo eram penas, feitas para aquecê-lo, protegê-lo da umidade e auxiliar no voo. Mas uma coisa sua mãe não sabia explicar: sua coloração negra. Ele era o primeiro cisne negro da história, e tudo porque antes dele nenhum cisne havia voado tão perto do sol, e essa proximidade com raios UV causou uma mutação em suas células que passaram a produzir penas negras e não brancas. Isso o deixou extremamente triste e cabisbaixo, ele se sentia o próprio patinho feio. Mas não foi exatamente isso que aconteceu. Devido a sua cor diferenciada, todas as fêmeas agora se interessavam mais por ele do que por qualquer outro, e com isso ele teve muitos e muitos filhos, alguns deles brancos como as mães e outros como ele, e tudo isso resultado dos cruzamentos e das recombinações dos seus genes. Com o tempo, ele já não era mais o único cisne negro.... ele não era mais um patinho feio! (EDU, grifos nossos).

Cabe observar que os erros e os pontos indicados no conto não refletem o pensamento do licenciando-autor, eles foram introduzidos com o objetivo de provocar uma discussão com os alunos leitores-imaginários. Propondo uma leitura problematizadora e interativa, vemos que Edu pretende reconstruir o discurso evolucionista mais próximo da cultura científica. 


\section{A abordagem pedagógica do conto no ensino de ciências}

Uma vez construído o texto, passamos a análise do plano de ensino feito pelo licenciando, sendo, por nós, organizado em um quadro com indicações numéricas das estratégias. O conto foi direcionado ao Ensino Fundamental e, assim, ele estabelece a criação de condições da leitura no contexto escolar, apontando abertura de espaços para a compreensão de diferentes sentidos, previstos e imagináveis.

\begin{tabular}{|c|c|}
\hline \multicolumn{2}{|r|}{ PLANO DE ENSINO - ESTRATÉGIAS } \\
\hline 1 & $\begin{array}{c}\text { Início da aula (geminada) com questionamentos aos alunos sobre "Evolução: o que é? } \\
\text { Como funciona?". }\end{array}$ \\
\hline 2 & $\begin{array}{l}\text { Após levantar as informações sobre o que os alunos pensam sobre o tema, solicitar } \\
\text { a leitura em duplas, ou em trios, do texto A EVOLUÇÃO DO OVO, solicitando que } \\
\text { destaquem no texto pontos que façam menção à evolução. }\end{array}$ \\
\hline 3 & $\begin{array}{l}\text { Após a leitura, verificar quais os pontos sobre evolução os alunos elencaram. Anotar no } \\
\text { quadro-negro. Proceder a aula expositiva, utilizando-se de material didático e recursos } \\
\text { disponíveis em sala, sobre evolução. }\end{array}$ \\
\hline 4 & $\begin{array}{l}\text { Aula interdisciplinar abordando tópicos da história e da genética (que estejam } \\
\text { relacionados ao conteúdo) - histórico das teorias da evolução, Darwin, genética. }\end{array}$ \\
\hline 5 & $\begin{array}{l}\text { Para cada série, adequar o aprofundamento dos conteúdos conforme a idade e os } \\
\text { conhecimentos prévios dos alunos. }\end{array}$ \\
\hline 6 & $\begin{array}{l}\text { Após a aula ministrada, verificar as anotações no quadro sobre quais os pontos } \\
\text { abordados pelos alunos (até, no máximo, o meio da segunda aula). }\end{array}$ \\
\hline 7 & $\begin{array}{c}\text { Refazer a leitura do texto, mas agora evidenciando os possíveis pontos/conceitos/ } \\
\text { menções sobre evolução que ficaram fora da primeira lista (seleção sexual, } \\
\text { cruzamentos e tópicos da genética etc.). }\end{array}$ \\
\hline 8 & $\begin{array}{l}\text { Solicitar que os alunos identifiquem os erros presentes na história lida levolução } \\
\text { rápida? seleção direcional? erros biológicos?). }\end{array}$ \\
\hline 9 & $\begin{array}{l}\text { Discussão sobre os erros apontados (informar/questionar sobre os erros, ou mesmo } \\
\text { pontos, sobre a evolução, que os alunos possam ter deixado passar). }\end{array}$ \\
\hline 10 & $\begin{array}{l}\text { Exercício de fixação para resolução em casa - solicitar que os alunos reescrevam as } \\
\text { partes do texto que apresentam erros, adequando-os às teorias e ao conteúdo correto } \\
\text { da evolução (EDU, grifos nossos). }\end{array}$ \\
\hline
\end{tabular}

Nas estratégias, compreendemos que a intervenção docente parece problematizar o conhecimento com vistas a considerar a memória discursiva dos estudantes, ao mencionar que pretende buscar as interpretações da classe sobre o tema, auxiliadas pela leitura do texto (1 e 2). Por consequência, o licenciando mostra a incompletude do texto ao propor uma aula expositiva e outros procedimentos didáticos que possam abranger o tema e ajudá-lo a fundamentar sobre o assunto em questão e, ainda, indica que seria ideal que o professor adequasse a leitura do texto de acordo com as séries do ensino básico, o que demonstra uma visão sistêmica de abordagem do conhecimento, ao passo que ele não compartimentaliza ou fragmenta o discurso apenas para uma série de ensino (3 e 4). 
Por conseguinte, observamos que na construção do conhecimento, ele pretende ponderar os não ditos do texto, denotando a compreensão de que a linguagem não é transparente. De nossa parte, podemos dizer que esse nível de construção textual reflete a preocupação do licenciando-autor com a identificação entre o leitor virtual e o real que poderá ser manifestada no texto, isto é, a necessidade do seu estudante-leitor realizar uma leitura global do texto, em ver o texto como unidade do discurso e da sua percepção do discurso da evolução como um todo que apenas o texto não daria conta de resolver (5,6 e 7).

Em seguida, reparamos que a retificação do erro, como propõe Bachelard (1996), significa uma estratégia do estudante na construção do conhecimento, preocupada em romper com o conhecimento espontâneo, com os eventuais erros conceituais e concepções alternativas que uma interpretação superficial do texto poderia promover. O que, por outro lado, instiga uma reflexão sobre o processo de leitura capaz de possibilitar uma formação crítica dos estudantes (8 e 9).

Por último, observamos que o futuro professor indica uma forma de apropriação do conhecimento científico pelo estudante, que poderia ser por meio da reconstrução do texto (10). Tal aspecto é importante, uma vez que "ensinar significa trabalhar o efeito leitor com o próprio aprendiz. E isto visa interferir na imagem que ele tem de texto e de leitura. Para isso é preciso mexer com a capacidade que esse sujeito tem de construir arquivos" (ORLANDI, 2001, p.70). Resta, assim, criar condições para auxiliar a compreensão de um texto a fim de que o conhecimento científico possa fazer parte da memória discursiva e, consequentemente, da realidade cotidiana. Percebemos no plano de ensino um sentido de leitura que se constitui por uma abertura importante para estabelecer interação entre os sujeitos para a apropriação do conhecimento científico no espaço escolar.

\section{CAMINHOS E HORIZONTES PARA UMA APROXIMAC̣ÃO ENTRE LEITURA E LITERATURA NO ENSINO DE CIÊNCIAS}

A leitura tem-nos mostrado uma série de possibilidades e desafios que devemos enfrentar para construir um conhecimento mais próximo da realidade da ciência e, nessa direção, queremos sublinhar algumas considerações.

Com efeito, é preciso ressaltar que ao realizar essa atividade, não esperávamos que surgisse uma heterogeneidade de propostas abarcadas por outros modos de leitura que poderiam fugir dos moldes acadêmicos por vezes presos em um discurso científico que se limita à produção e à leitura de artigos técnicos e científicos. Talvez, por isso mesmo, fomos surpreendidos por esses licenciandos que buscaram fora do discurso científico outras alternativas para a sala de aula. Nesse sentido, cabe indicar ser preciso, na formação dos professores de ciências, considerar essas outras possibilidades de aprendizagem com vistas a tornar o professor mais autônomo e a permitir que aflorem os significados de o "porquê" e do "como" ensinar. 
Além disso, mais importante do que levantar erros e concepções alternativas sobre a Evolução Biológica, é preciso encontrar caminhos para mediar nos contextos de ensino um conhecimento mais próximo da realidade científica. Julgamos ser importante que o professor, ao ensinar, ao mesmo tempo participe ativamente desse processo, como alguém que expõe seu gosto e participa da leitura "tendo para com o texto a mesma sensibilidade e atitude crítica que espera de seus alunos. Para seu trabalho prático, os critérios de seleção de textos devem ser, entre outros, aqueles decorrentes da sua "frequentação de leitura"' (MAGNANI, 2011, p.141).

No presente estudo, por exemplo, observamos um princípio epistemológico de considerar a produção do conhecimento como uma retificação do saber, que abrange possibilidades de participação dos alunos e que, ao mesmo tempo, não relega o funcionamento da cultura escolar, mas cria as condições de produção da leitura. É indiscutível que escrever o conto permitiu ao aluno envolver-se com aspectos extratextuais (manifestação cultural, social, científica), intratextuais (criação, imaginação, personagens) e intertextuais (relação com outros textos) que pulularam por meio da sua liberdade de produção artística. Defendemos que a proposta possibilitou-lhe refletir em novos horizontes e que, por consequência, ao propor a leitura de um texto literário, considerou os ditos e os não ditos, as expressões culturais e científicas que muitas vezes o ensino não é capaz de abarcar com plenitude.

No caminho percorrido, talvez seja pertinente, como professores, que também possamos "sair do ovo" que nos mantêm protegidos das adversidades e que estabelece, no processo de ensino, uma cultura acomodada, intocável e legitimada por um discurso escolar fundamentalmente autoritário. Em contraposição, propomos enfrentar as dificuldades levando em conta as possibilidades de uma prática docente que assuma posições reflexivas e interferências nos textos que temos em mãos, a fim de que não sejamos mais professores presos dentro da casca que nos mantém em um funcionamento esperado ou previsto, e que nos torna assujeitados.

Em suma, a prática de leitura-escrita no ensino de ciências pode contribuir para a formação de sujeitos-autores, a começar pelo professor. Mas, para que isso aconteça, é preciso sair do abrigo tradicionalmente estabelecido e encarar a realidade intervencionista capaz de nos tornar singulares, entre tantos outros sujeitos, no mundo escolar.

\section{NOTA}

${ }^{1}$ Anderson, H. C. O Patinho Feio (1843). In: LOBATO, Monteiro. Contos de Anderson. $8^{a}$ ed. São Paulo, SP: Brasliense, 1973.

\section{REFERÊNCIAS}

ALMEIDA, A. V.; FALCAO, J. T. R. As Teorias de Lamarck e Darwin nos livros didáticos de biologia no Brasil. Ciência e Educação, São Paulo, v. 16, p. 649-665, 2010. 
- A estrutura histórico-conceitual dos programas de pesquisa de Darwin e Lamarck e sua transposição para o ambiente escolar. Ciência \& Educaşão, São Paulo, v.11, n.1, p. 17-32, 2005.

ALMEIDA, M.J.P.; CASSIANI, S.; e OLIVEIRA, O.B. Leitura e Escrita em Aulas de Ciências: Luz Calor e fotossíntese nas mediações escolares. Florianópolis: Letras. 2008.

; NARDI, R.; BOZELLI, F. C. A diversidade de interpretações como fator constituinte da formação docente: leitura e observação. Educar em Revista, Curitiba, v. 34, p. 95-109. 2009.

; SILVA, H.C. da; MACHADO, J.L.M. Condições de Produção da Leitura na educação em

Física. In: Revista Brasileira de Pesquisa em Educação em Ciências, Porto Alegre, v. 1, n. 1, p. 5-17, 2001. ; SORPRESO, T. P. Dispositivo analítico para compreensão da leitura de diferentes tipos textuais: exemplos referentes à Física. Pro-Posições, Campinas, v. 22, p. 1-12, 2011.

AMORIM, M.C.O; ROSA, V. L. A Evolução Biológica e seu Ensino nos encontros Nacionais de Pesquisa em Educação em Ciências (ENPEC). In: ENCONTRO NACIONAL DE PESQUISA EM EDUCAÇÃO EM CIÊNCIAS, 7., 2009. Florianópolis. Anais... Florianópolis: ENPEC, 2009.

ANDRADE, I. B.; MARTINS, I. Discursos de professores de ciências sobre leitura. Investigações em ensino de ciências, Porto Alegre, v. 11, n. 2, p. 121-155, 2006.

BACHELARD, G. A Formação do Espírito Científico. Rio de Janeiro: Contraponto, 1996.

BIZZO, N. M. V; EL-HANI, C. N. O Arranjo Curricular do Ensino de Evolução e as Relações Entre os Trabalhos de Charles Darwin e Gregor Mendel. Revista de Filosofia e História da Biologia, São Paulo, v.4, p.235-257, 2009.

BORGES, R. M. R.; LIMA, V. M. R. Tendências contemporâneas no ensino de Biologia no Brasil. Revista Electrónica de Enseãnz̧a de las Ciências, Vigo, v. 6, n. 1, 2007.

CANDIDO, A. Literatura e sociedade : estudos de teoria e história literária. 8 ed. São Paulo: T. A. Queiroz Editor, 2000.

CASSIANI, S; Condições de Produção de Sentidos em Textos Didáticos de Ciências. Ensaio. Pesquisa em Educação em Ciências, Belo Horizonte, v. 8, p. 1-14, 2006.

; NASCIMENTO, T. G. Um diálogo com as histórias de leituras de futuros professores de ciências. Pro-Posições, Campinas, v. 17, p. 105-116, 2006.

COSTA, L.O.; MELO, P.L.C.; TEIXEIRA, F.M. Reflexões acerca das diferentes visões de alunos do ensino médio sobre a origem da diversidade biológica. Ciência e Educação, São Paulo, v. 17, p. 115-128, 2011.

DA-GLORIA, P. Seria a teoria da evolução darwiniana domínio exclusivo dos biólogos? Implicações da evolução biológica para as ciências humanas. Revista da Biologia. São Paulo, v. 3, p.1-5, 2009.

DIAS, R. H.A.; ALMEIDA, M.J. P. M. A Repetição em Interpretações de Licenciandos em Física ao Lerem as Revistas Ciência Hoje e Pesquisa Fapesp. Ensaio - Pesquisa em Educação em Ciências, Belo Horizonte, v. 12, p. 51-64, 2010.

FERREIRA, L.N.A ; QUEIROZ, S. L. Autoria no ensino de química: análise de textos escritos por alunos de graduação. Ciência e Educação, São Paulo, v. 17, p. 541-558, 2011.

FUTUYMA D. J. Evolução, ciência e sociedade: $48^{\circ}$ Congresso Nacional de Genética. Ed. Exclusiva. São Paulo: SBG, 2002.

GALLO, S. L. Como o texto se produ₹: uma perspectiva discursiva. Blumenau: Nova Letra, 2008.

GIRALDELLI, C.G. C. M.; ALMEIDA, M. J. P. M. Leitura Coletiva de um Texto de Literatura Infantil no Ensino Fundamental: algumas mediações pensando o ensino das ciências. Ensaio Pesquisa em Educação em Ciências, Belo Horizonte, v. 10, p. 1-19, 2008.

GOEDERT, L. A formação do professor da UFSC e o ensino de evolução biológica. 2004.122f. Dissertação (Mestrado em Educação Científica e Tecnológica) - Programa de Pós-Graduação em Educação Científica e Tecnológica da UFSC. Florianópolis: UFSC, 2004.

LAJOLO, M. O que é literatura. $12^{\mathrm{a}}$ ed. São Paulo: Brasiliense, 1990.

LOPES, A. C. Conhecimento escolar: ciência e cotidiano. Rio de Janeiro: EdUERJ, 1999.

MAGNANI, M.R.M. Leitura, literatura e escola: sobre a formação do gosto (2001). 1ª Reimpressão. São Paulo, SP: Martins Fontes, 2011.

MEGHLIORATTI. F.A. História da construção do conceito de evolução biológica: possibilidades de uma percepção dinâmica das ciências pelos professores de biologia. 2004. 272f. Dissertação (Mestrado 
no Ensino de Ciências) - Faculdade de Ciências, Universidade da Universidade Estadual Paulista, Bauru: 2004.

MICHINEL, J. L; Condiciones de producción de la lectura e implicaciones para la enseñanza de física en la universidad. Pro-Posições, Campinas, FE, UNICAMP, Campinas, v. 17, n. 1, p. 49, 2006.

NASCIMENTO, T. G.; MARTINS, I. Leituras de textos da Revista Ciência em Tela por professores de ciências. Ensaio - Pesquisa em Educação em Ciências, Belo Horizonte, v. 13, p. 1-25, 2011.

OLEQUES, L.C.; BARTHOLOMEI-SANTOS, M. L.; BOER, N. Evolução biológica: percepções de professores de biologia. Revista Electrónica de Enseñanza de las Ciencias, Vigo, v. 10, p. 243-264, 2011.

ORLANDI, E. Discurso e leitura. $9^{a}$ ed. São Paulo: Cortez, 2012.

. A. Linguagem e seu funcionamento: as formas do discurso, $4^{\mathrm{a}}$ ed. Campinas: Pontes, 2006.

Análise de discurso: princípios e procedimentos. Campinas: Pontes, 2003.

Discurso e texto: formação e circulação dos sentidos. Campinas: Pontes, 2001.

OLIVEIRA, O. B. Em defesa da leitura de textos históricos na formação de professores de ciências. Pro-Posições, Campinas, v.22, n.1, p. 71-82, 2011.

PALCHA, L. S. A leitura e as formações discursivas na formação docente: entre o discurso da evolução biológica e as estratégias no ensino de ciências. 2012. 218f. Dissertação (Mestrado em Educação). Universidade Federal do Paraná: Curitiba, 2012.

PÊCHEUX, M. Semântica e Discurso: uma crítica à afirmação do óbvio. $4^{a}$ ed. Campinas: Editora da UNICAMP, 2009.

PORTO, P. R. A.; FALCAO, E. B. M. Teorias da origem e evolução da vida: dilemas e desafios no ensino médio. Ensaio - Pesquisa em Educaşão em Ciências, Belo Horizonte, 2010.

SEPÚLVEDA, C.; EL-HANI, C. N. Quando Visões de Mundo se Encontram: Religião e Ciência na Trajetória de Formação de Alunos Protestantes de uma Licenciatura em Ciências Biológicas. Investigaçoes em Ensino de Ciências, Porto Alegre. v. 9, n. 2, p. 137-175, 2004.

SILVA, H.C.; ALMEIDA, M.J. P. M. O deslocamento de aspectos do funcionamento do discurso pedagógico pela leitura de textos de divulgação científica em aulas de física. , Vigo, vol. 4, n. 3, p. 1-25, 2005.

ZANOTELLO, M.; Leitura de textos originais de cientistas por estudantes do ensino superior. Ciência e Educação, São Paulo, v. 17, p. 987-1013, 2011. 